\title{
Quando o "bello sexo" se conecta: reflexões de Soledad Acosta de Samper sobre o ensino das mulheres no Congreso Pedagógico Hispano-Portugués-Americano (1892)
}

\begin{abstract}
Resumo: O presente artigo tem por objetivo discutir a trajetória da viagem à Espanha e a participação da intelectual colombiana Soledad Acosta de Samper no Congreso Pedagógico Hispano-Portugués-Americano em Madri, em 1892, em que a autora proferiu o trabalho "Concepto y límites de la educación de la mujer y de la aptitud profesional de ésta" na sessão exclusiva para discutir o ensino profissionalizante das mulheres. Desta forma, lançamos mão das reflexões inerentes à História das Relações de Gênero, à História Intelectual e aos estudos das escritas de si, a fim de ponderarmos sobre as suas reflexões acerca do ensino das mulheres e o papel do governo em relação a este. Entende-se que a sua participação no congresso citado se deve ao seu reconhecimento como intelectual e sua inserção em redes de sociabilidade masculinas, em um contexto de reaproximação da Espanha com as repúblicas latino-americanas.
\end{abstract}

Palavras-chave: História das Relações de Gênero, História Intelectual, relatos de viagem.

\section{When the "beautiful sex" connects: reflections by Soledad Acosta de Samper about the teaching of women in the Spanish-Portuguese- American-Pedagogical Congress (1892)}

\begin{abstract}
This article aims to discuss the trajectory of the trip to Spain and the participation of the Colombian intellectual Soledad Acosta de Samper in the Spanish-Portuguese-American Pedagogical Congress in Madrid, in 1892, in which the author contributed with the work "Concept and limits of women's education and professional aptitude" in the exclusive session to discuss the professional education of women. In this way, we make use of the reflections inherent in the History of Gender Relations, the Intellectual History, and the studies of the writings of themselves, in order to consider their reflections on the teaching of women and the role of the government in relation to this. It is understood that her participation in the mentioned congress is due to her recognition as an intellectual and her insertion in networks of male sociability, in a context of rapprochement of Spain with the Latin American republics.
\end{abstract}

Keywords: History of Gender Relations, Intellectual History, travel writing.

Artigo recebido em: 07/08/2020

Artigo aprovado para publicação em: 07/04/2021

\footnotetext{
${ }^{1}$ Mestranda em História Social pela Universidade de São Paulo, São Paulo, Brasil, com a pesquisa intitulada Soledad Acosta de Samper entre mundos: relatos de uma viajante colombiana (1892). Bolsista CAPES. Contato: thais.carneiro@usp.br.
} 


\section{Introdução}

A colombiana Soledad Acosta de Samper (1833-1913) é considerada um exemplo do silenciamento historiográfico (SOIHET, PEDRO, 2007), de acordo com a crítica literária espanhola Montserrat Ordóñez citando que por mais que a escritora tivesse uma produção considerável perpassando a literatura e a historiografia, fora posicionada à margem da história da literatura colombiana. (ORDÓÑEZ, 2000 apud ACOSTA DE SAMPER, 2004)

O paradoxo desta figura histórica reside no fato de que por mais que tenha contribuído de forma significativa para o pensamento latino-americano, há uma dificuldade de acesso às suas obras. Uma das possíveis explicações seria a falta de interesse de editoras e centros de pesquisa em socializar suas produções, por exemplo. (LIMA, 2017)

Sua produção prolífica a permitiu atuar como jornalista, tradutora, escritora de crônicas de viagem e quadros de costumes, biógrafa, crítica literária e ensaísta. A autora fundou 5 jornais, escreveu 35 romances e 50 crônicas. Dedicamo-nos à descrição da amplitude de sua carreira para trazermos ao debate a diversidade de suas ações e compreendermos o seu reconhecimento à época. Vale a ressalva de que não nos alinhamos ao discurso do extraordinário, entendendo Soledad como uma mulher à frente de seu tempo. Outras contemporâneas, como a brasileira Nísia Floresta, a cubana Gertrudis Gómes de Avellaneda e a argentina Eduarda Mansilla de Garcia, tiveram trajetórias na vida pública por meio de seus escritos que corroboraram para tal interpretação de que estiveram inseridas em um jogo de negociações de seus papéis sociais (SCATENA FRANCO, 2008).

Sendo assim, partimos da perspectiva de que a sua jornada como mulher intelectual foi possibilitada por uma série de questões, entre elas as redes de sociabilidade nas quais a autora esteve inserida. Em fins do século XIX, Acosta de Samper representou uma exceção em um mundo de letras predominantemente masculino. De certa forma, a sua inclusão nesse círculo teve a chancela desses homens, o que emerge de modo mais claro na sua participação na vida pública.

Dentre os escritos de Acosta de Samper, destacamos trabalhos como a biografia de "General Joaquín París" (1883), "Aptitud de la mujer para ejercer todas las profesiones: memoria presentada en el Congreso Pedagógico hispano-lusitano-americano reunido" (1892), "Novelas y cuadros de la vida suramericana" (2004), "La Mujer: revista quincenal exclusivamente 
redactada para señoras y señoritas" (1879), "Diario íntimo y otros escritos de Soledad Acosta de Samper" (2003). Por mais que tenha dialogado com a historiografia, a literatura e a "escrita de si", os temas centrais que atravessaram o trabalho intelectual da escritora são a educação e as mulheres. Acosta de Samper defendeu uma formação profissional e intelectual feminina pautada nas mesmas diretrizes intelectuais da educação dos homens, porém ressaltando a necessidade de uma clivagem de classe para diferenciar o ensino oferecido.

Diante da diversidade e complexidade do seu trabalho, o presente artigo traça um recorte da sua viagem à Espanha, em 1892, para participar das comemorações do IV Centenário de Conquista da América, sobre o qual a autora produziu a obra Viaje a España, dividida em dois tomos. Constituindo seus relatos de viagem, a sua escrita perpassou narrativas de cunho pessoal, bem como de processos históricos de cada cidade que visita.

Narrado com uma voz objetiva e impessoal, os relatos de viagem trouxeram a autora como uma viajante erudita, conhecedora da história local, descrevendo lugares e relatando acontecimentos, embasando seus escritos com citações de historiadores e outros viajantes. (HINCAPIÉ, 2007) Os relatos de viagem acabaram por se afastar da norma vigente e trouxeram olhares distintos sobre as relações sociais e a possibilidade de enxergar desigualdades. Eles captaram elementos do cotidiano. Mais que a experiência em si, os escritos apontaram formas de representá-las para o público leitor.

Nessa viagem, que teve a duração de dois meses e meio, principalmente utilizando o trem como meio de transporte, Soledad prestes a completar sessenta anos, viúva há quatro anos do literato colombiano José María Samper, esteve acompanhada de sua filha Blanca Leonor, de trinta anos. Acosta de Samper foi convidada a participar de três eventos: Congreso Pedagógico HispanoPortugués-Americano e o Congreso Literario Hispanoamericano, ambos em Madri, e o IX Congreso Internacional de Americanistas, em Huelva. Porém, neste artigo nos deteremos a aprofundar o debate traçado no primeiro congresso citado para refletirmos sobre sua perspectiva sobre a educação das mulheres.

Por mais que os seus relatos de viagem tenham sido publicizados na obra Viaje a España, distribuída em dois tomos, compreendemos que se trata de um documento que se estende ao âmbito privado também. Desta forma, a obra nos auxilia na compreensão dos bastidores dessas confraternizações. Em diálogo com essa perspectiva, valemo-nos da análise da documentação como fonte complementar, produzida por sua filha, Blanca Leonor Acosta de Samper, em que 
registrou em primeira pessoa suas impressões de viagem em forma epistolar' direcionada à sua tia Maria, carregada de certo tom de informalidade, trazendo trechos sobre o cotidiano dos congressos e os personagens envolvidos por meio de comentários, muitas vezes jocosos e irônicos ${ }^{2}$. Um exemplo a ser citado é a forma como ela enxerga a vestimenta de outras mulheres, concluindo que “entre parentesis les diré que mis vestidos han sidos los mejores de todos, pues las demás señoras no saben se vestir" ${ }^{3}$ (SAMPER, 1892, p. 61). A referência à moda é algo recorrente nos discursos de Blanca e de Soledad como forma não só de registrar o que experienciam, mas como construção de uma narrativa de civilidade. Valemo-nos, por fim, dos anais produzidos pelos respectivos congressos, em que estão elencadas as memórias redigidas pela escritora colombiana ${ }^{4}$.

A escolha do Congreso Pedagógico Hispano-Portugués-Americano se deve ao objetivo de compreender a sua condição de passabilidade em um meio intelectual masculino, no sentido de ocupar um lugar que a priori não seria possível para mulheres, dentro do contexto histórico-social em que a autora estava inserida. Por outro lado, dedicamo-nos ao esforço de não normatizar a condição de passabilidade ${ }^{5}$ desenvolvida por Soledad, estendendo-a a toda sociedade, sob o risco de relativizarmos uma série de tensões imbricadas nas relações sociais, em fins do século XIX, não só entre gêneros,mas também na articulação social em meio às disputas de poder diante das novas configurações da Espanha e da América Latina. Para tanto, lançamos mão das reflexões concernentes à História Intelectual e à História das Relações de Gênero.

Seguiremos as discussões sobre configurações de rede de sociabilidade a partir da ótica da História Intelectual para compreendermos como as relações estabelecidas em ocasiões como salões literários, por exemplo, foram fundamentais para ampliação de sua área de atuação e o reconhecimento de seu trabalho como literata e intelectual colombiana. A partir disso, a importância das possibilidades permitidas a ela reverberam em seu discurso no Congreso Pedagógico Hispano-Portugués-Americano, em defesa de uma educação profissional para as mulheres.

\footnotetext{
2 Provavelmente, irmã de seu pai, pois Soledad era a filha única do casamento de Carolina Kemble e Joaquín Acosta.

3 "Entre parênteses lhes direi que meus vestidos foram os melhores de todos, pois as demais senhoras não sabem se vestir". (tradução nossa)

4 Ao nos referirmos ao termo memórias, utilizados nos anais dos eventos e por estudiosos (as) latino-americanos (as), apreendemos que se trata de um gênero textual próximo ao de trabalhos acadêmicos atualmente apresentados em congressos. Há um intuito de divulgação científica, porém o formato acaba por se colocar em um intermediário entre o ensaio e o artigo científico.

5 Termo cunhado pela comunidade trans ao se referir à performance de gênero. (DUQUE, 2013)
} 


\section{"Tomar el chocolate": reflexões sobre as configurações de uma rede de sociabilidade}

Para compreendermos a relevância das ditas redes de sociabilidade, partimos da narrativa de Acosta de Samper de um episódio em seu diário de viagem, uma visita à casa da literata espanhola Emilia Pardo Bazán para "tomar chocolate", o que nos é apresentado como uma espécie de visita íntima à casa de uma amiga, revela-se um grandioso evento em que grandes nomes da literatura e da política à época estão reunidos. Antes de adentrarmos às minúcias da visita, dedicamo-nos ao posicionamento da História Intelectual, ferramenta metodológica utilizada neste artigo.

Partimos da premissa do historiador francês Jean-François Sirinelli de que a "história dos intelectuais tornou-se assim, em poucos anos, um campo histórico autônomo que, longe de se fechar sobre si mesmo, é um campo aberto, situado no cruzamento das histórias política, social e cultural.” (SIRINELLI apud RÉMOND, 2003, p. 232)

Essa hibridização acaba por borrar as fronteiras da categoria, permitindo o trânsito em diferentes linhas de pesquisa, o que, por um lado, ampliaria a complexidade da discussão, atribuindo mais camadas de análise e aprofundando o debate, e por outro, pode tornar-se um campo minado disputado por diferentes frentes e deslocado de um foco analítico. A escolha da categoria para o debate sobre a jornada empreendida pela colombiana Soledad Acosta de Samper durante a sua viagem a Espanha, em 1892, deve-se ao fato de que ela é reconhecida por seus pares como intelectual e literata, o que propicia a sua participação nos congressos citados. O reconhecimento da sua figura como historiadora, membro da Academia de História de Caracas, reforça a concepção como intelectual. Diante disso, vale a ressalva de que há um meio em que esses intelectuais circulam e se relacionam entre os seus pares.

Não tomemos aqui a categoria rede de sociabilidade como um elemento estático, já que esta se reconfigurou em meio ao contexto histórico na qual os sujeitos estavam inseridos. Por mais que seja difícil de apreender as estruturas de sociabilidades, é necessário traçá-las a partir de conexões entre um grupo de intelectuais que se aproximaram por sensibilidade ideológica ou cultural comuns. Por outro lado, as relações podem se estabelecer por cunho político, tornando a aproximação estratégica. Como colocou Sirinelli, “os 'salões', na fronteira entre os dois séculos, 
constituíam uma casa importante no jogo de ludo dos intelectuais, com suas musas da sociabilidade”. (SIRINELLI apud RÉMOND, 2003, p. 249) Portanto, os salões constituíram um espaço para ver e ser visto, de desenvolvimento de conexões e admirações. Estendendo-nos sobre a argumentação de Sirinelli, arriscamos colocar os "salões" como um espaço de performance para esses intelectuais, em que eles se situaram no mundo para os seus pares.

Para pensarmos as conexões possibilitadas e reforçadas em encontros de intelectuais e literatos no âmbito privado, consolidando-se determinadas configurações de rede de sociabilidade, tomemos como exemplo um dos episódios narrados em Viaje a España: um convite a "tomar um chocolate" na casa da literata espanhola Emilia Pardo Bazán, consagrada à época, com quem Acosta de Samper participou no Congresso Pedagógico como colegas ${ }^{6}$. Esses exemplos nos interessa para aprofundarmos a reflexão dos meandros envolvidos na articulação entre as esferas pública e privada, a partir dessas confraternizações entre seus pares, e para compreendermos a sua inserção enquanto mulher latino-americana no cenário europeu ocidental, em um mundo das letras marcadamente masculino, que já havia lhe consagrado. Utilizamos esse evento como ponto de partida para compreendermos a atuação das referidas personalidades nos congressos que partilharam da presença com Soledad.

A visita à casa da escritora Emília Pardo Bazán foi celebrada de modo a abrir um dos capítulos de Viaje a España, em que a literata colombiana introduz a questão, dizendo-nos que "la afamada escritora doña Emilia Pardo Bazán nos convidó a que fuésemos 'á tomar el chocolate' una noche en su casa de la calle San Bernardo"(ACOSTA DE SAMPER, 1893, II, p. 214)7. Há um tom informal, que constrói no leitor a ideia de uma visita íntima a uma das escritoras mais populares e consagradas da Espanha à época. Soledad construiu a narrativa de um encontro de amigas que praticaram o singelo gesto de tomar chocolate. Porém, ela deu continuidade à sua descrição ao chegar à casa de Pardo Bazán ao referir-se a uma celebração que não condizia com essa perspectiva. Seu olhar se lançou sobre a decoração da casa, ressaltando a sua sofisticação,

\footnotetext{
${ }^{6}$ Emilia Pardo Bazán foi uma das literatas que participou do Congreso Pedagógico Hispano-Portugués-Americano, em que teve sua profissão identificada como publicitária. Sua consagração lhe logrou, posteriormente ao período narrado, o título de Condessa de Pardo Bazán (1908). Viúva desde 1884, a crítica literária espanhola foi considerada uma das introdutoras do naturalismo na o país. Em 1892, fundou e se tornou diretora do periódico Biblioteca de La Mujer.

7 “A famosa escritora dona Emilia Pardo Bazán nos convidou para tomarmos um chocolate quente certa noite em sua casa na rua São Bernardo.” (tradução nossa)
} 
"en los artísticamente decorados salones de la gran literata, que reside con sua madre, sus tres hijos y una tía, encontrámos reunidos gran número de escritores y personas notables de Madrid. Encuanto á señoras, no habia allí más que las de la casa y nosotras dos." (ACOSTA DE SAMPER, 1893, II, p. 215)

O fato de poucas mulheres frequentarem a celebração dá o tom de exclusividade necessária ao encontro, aparentemente conferindo uma conotação de transgressão de um mundo das letras marcado pela masculinidade. Por outro lado, a narrativa nos traz a perspectiva oposta de que não haveria uma transgressão, já que pouquíssimas mulheres ocupavam o ambiente. Ao pontuar que apenas ela e sua filha Blanca eram alheias ao ambiente da casa, a autora se apresentou como a eleita de Pardo Bazán.

Soledad seguiu sua descrição ao falar da roupa da anfitriã, "Doña Emilia vestía traje de ceremonia, de raso blanco, bordado de sedas de colores, guarnecido de ricos encajes y cubiertos de diamantes." (ACOSTA DE SAMPER, 1893, II, p. 215) Diferentemente das descrições de vestimentas de outras mulheres, realizadas por Acosta de Samper, Pardo Bazán parece não só seguir o código de vestimenta como também portar-se de modo luxuoso. Ao nos contar isto, Soledad alça o seu compromisso de "tomar el chocolate" em uma sofisticada e restrita celebração, permitida aos "eleitos".

Estendemos a questão para refletirmos sobre o contexto social de grandes transformações em que tanto Soledad quanto Blanca Leonor estavam inseridas, em um momento em que a burguesia emergente utilizava-se do dinheiro como ferramenta de aquisição de determinados signos da nobreza tradicional, entre eles, a forma de se apresentar ao mundo de modo luxuoso. De acordo com Gilda de Mello e Souza,

... a arrivista começa a ofuscar a 'dama exemplar' através do luxo dos vestidos... uma nova barreira se interpõe entre as classes, ainda mais difícil de transpor que a antiga, pois já não se apoia na ostentação da riqueza, mas no polimento das maneiras, na composição elaborada dos gestos, enfim, no elemento dinâmico da moda. A distinção econômica do luxo cede lugar à distinção estética da elegância. (SOUZA, 1987, p. 116, 132 e 134)

Isto posto, a autora reflete sobre um novo critério de distinção diante da reacomodação dos grupos sociais em meio à emergência da burguesia, que deixa de ser a ostentação da riqueza para

\footnotetext{
8 "Os salões da grande literata, artisticamente decorados, em que residia com sua mãe, seus três filhos e uma tia, reuniram um grande número de escritores e pessoas notáveis de Madrid. Enquanto a senhoras, não havia ali mais do que as da casa e nós duas" (tradução nossa).

9 "Dona Emília vestia traje de cerimônia, de cetim branco, bordado de seda colorida, guarnecido de ricas rendas e coberto de diamantes." (tradução nossa)
} 
construir uma concepção de elegância, vinculada a "boas maneiras". Esse debate também está atrelado à concepção de civilização, de acordo com Nobert Elias, que se utiliza da expressão “ancestral civilite”". (ELIAS, 1994, p. 72)

O autor argumenta que na França do século XVIII, "duas ideias se fundem no conceito de civilização". A primeira traz a conotação de uma espécie de estado atingido pelas sociedades por meio de práticas de polidez e civilidade, atributos da aristocracia da corte. Aos que não atingiram esse estágio, compreendia-se que estavam sob o domínio da barbárie. A nova ideia que se incorpora a essa concepção no século XVIII é a de que a civilização deixa de ser um estado, para ser entendida como um processo em meio à emergência da burguesia.

Dessa forma, é recorrente nos discursos de Soledad e de sua filha Blanca Leonor a reflexão sobre as vestimentas de outros indivíduos, principalmente de mulheres, como mote para se discutir a temática sobre os bons costumes e a concepção de civilização. A elegância é sinônimo de civilização. Nesse caso, elas se dedicaram a comentar sobre vários indivíduos dentro dessa lógica. Por mais que nos conte que a presença feminina era exceção nos salões, a autora deixa claro que isso não é motivo para seu desconforto, já que muitos dos que estavam ali presentes faziam parte do seu círculo social. (ACOSTA DE SAMPER, 1893, II, p. 215)

Pelo contrário, parece-nos que a escritora colombiana ocupa o seu espaço social ao citar despretensiosamente uma série de nomes ao público leitor, que já tiveram suas conversas narradas no mesmo diário de viagem, como é o caso do peruano Ricardo Palma, do colombiano Ernesto Restrepo e do espanhol Marcelino Menéndez Pelayo. Referir-se como uma das poucas "eleitas" por Pardo Bazán foi uma estratégia não só para obter reconhecimento do seu público, mas de seus pares, tanto pela sua pertinência literária como pela sua conexão com a literata espanhola.

No caso de Soledad Acosta de Samper, objeto de estudo deste artigo, a circulação dessa mulher burguesa letrada por espaços tidos como masculinos marca a existência de zonas de negociação desses papéis de gênero, quebrando a perspectiva de mulheres extraordinárias, fora de seu tempo e contexto. Portanto, a leitura necessária é entender o próprio grupo social de mulheres viajantes letradas, do qual Acosta de Samper fazia parte. Levando-se em consideração o trabalho de Miriam Lifchitz Moreira Leite, em seu artigo "Mulheres Viajantes do século XIX”, de algum modo, essas mulheres ameaçam a norma ao adentrar um terreno entendido como masculino. Tendo em vista os relatos femininos, coloca que 
A principal semelhança entre os livros das mulheres viajantes é a grande capacidade de observação, que ultrapassa as diferentes circunstâncias singulares e as diferentes situações pessoais e políticas que enfrentaram, através do século XIX. Sejam elas modistas, que vinham "fazer a América", turistas, jornalistas, professoras, acompanhantes ou cientistas, provenientes dos países europeus ou dos Estados Unidos, todas têm grande cuidado e atenção às condições da vida do dia a dia, quando comparam situações vividas, no local de origem, com aquelas que procuram descrever e interpretar. (LEITE, 2000, p. 134)

Em suas andanças, Acosta de Samper se valeu dessas estratégias, escrevendo a relação construída com as paisagens espanholas como se o contato com os espaços históricos pudesse acender-lhe memórias: "me parecía soñar cuando resonaban en mi oído esos nombres históricos que evocaban tantos hechos magnos de nuestros antepasados ${ }^{10}$. (ACOSTA DE SAMPER, 1893, p. 104)

Há um olhar para esse passado em comum com a Espanha, algo que ela enquanto colombiana compartilha com a antiga Metrópole. Por outro lado, é necessário, pensar as tensões entre a circulação pelos espaços que essas mulheres viajantes vivenciaram para entendermos o jogo entre público e privado, masculino e feminino. Como coloca a historiadora Stella Maris Scatena Franco, em seu artigo "Viagem e gênero: tendências e contrapontos nos relatos de viagem de autoria feminina":

A tensão entre a reiteração de concepções convencionais e a quebra de alguns protocolos também se fez evidente em temas como a circulação pelos espaços, a colocação das mulheres no mercado de trabalho, a incursão no mundo das letras e os posicionamentos políticos. Tentavam manter um equilíbrio, no limite, bastante instável, e que às vezes parecia pender, se não para uma ruptura, ao menos para um deslocamento dos comportamentos e noções usuais. (FRANCO, 2017, p. 20)

São essas negociações de poderes e espaços que acabam municiados por tensões, que nos interessa pensar nessa circulação de pessoas e saberes.

\section{Quando o "bello sexo" se conecta}

A continuar o debate dessa conexão, tomamos a descrição da quinta sessão do Congreso Pedagógico Hispano-Português-Americano, sob o tema do ensino das mulheres, em que a

\footnotetext{
10 "Parecia-me sonhar quando ressoavam em meu ouvido esses nomes históricos, que evocavam tantos fatos magnos de nossos antepassados.” (tradução nossa)
} 
escritora espanhola Emilia Pardo Bazán participou junto com Acosta de Samper. Pardo Bazán apresentou o trabalho "Relaciones y diferencias entre la educación de la mujer y la del hombre", o qual foi criticado pela professora Ana María Solo de Zaldívar, que

\begin{abstract}
... se levantó para replicar a la señora Pardo Bazán, y que el único objeto que tuvo su discurso fue el de humillar la dignidad del sexo de la mujer ante el hombre. Aseguró que aquella que solo había nacido para agradar a este, sin otra misión que aquella en el mundo; dio a entender que la mujer solo valía por sus encantos físicos, y que era preciso dejarle todo trabajo intelectual al varón, rey del universo. Semejantes conceptos, que en otros países hubieran sido acogidos con indiferencia como vulgaridades pasadas de moda, produjo entusiasmo loco entre los oyentes masculinos y aun entre muchas de las damas allí presentes. Parecía que el salón se venía abajo con los aplausos que en él resonaban; y cada vez que la dicha señorita, que, como todas las españolas, es muy desparpajada y habla con facilidad y gracia natural, decía alguna chocarrería de mal gusto dirigido a la señora Pardo Bazán, muchos de lo que estaban en la plataforma de honor, detrás de aquella escritora, palmoteaban en señal de aprobación, lo cual me pareció el colmo de la descortesía y hasta falta de patriotismo. ${ }^{11}$ (ACOSTA DE SAMPER, 1893, II, p. 160-161)
\end{abstract}

Acosta de Samper narra o posicionamento da professora Solo de Zaldívar com desagrado diante das críticas impostas a Pardo Bazán, trazendo como argumento em oposição, a concepção de que o homem como o "rey del universo" deveria ficar com o trabalho intelectual e que a mulher "valía por sus encantos físicos". (ACOSTA DE SAMPER, 1893, II, p. 162)

A reação da plateia ao ovacionar Solo de Zaldívar a surpreende negativamente, pois argumenta que em outras nações, tamanha declaração seria entendida como vulgar e parte de um pensamento retrógrado e já teria caído em desuso. Seu incômodo é tamanho que compreende a situação como um desrespeito não só a Pardo Bazán, mas à nação espanhola. Seu alinhamento com a escritora é notável ao analisarmos a sua memória apresentada no mesmo congresso, que dialoga com a perspectiva de que homens e mulheres podem ocupar as mesmas atividades profissionais. Para a autora, parece contraproducente que em uma sessão voltada para o ensino das mulheres,

\footnotetext{
11 "levantou-se para replicar à senhora Pardo Bazán, e o único objetivo que teve seu discurso foi o de humilhar a dignidade da mulher perante o homem. Assegurou que aquela só havia nascido para agradar a este, sem outra missão que aquela no mundo; deu a entender que a mulher só valia por seus encantos físicos, e que era preciso deixar todo trabalho intelectual ao varão, rei do universo. Semelhantes conceitos, que em outros países teriam sido acolhidos com indiferença como vulgaridades fora de moda, produziu um entusiasmo louco entre os ouvintes masculinos e mesmo entre muitas das damas ali presentes. Parecia que o salão se vinha abaixo com os aplausos que nele ressoavam; e cada vez que a dita senhorita [referência à Solo de Zaldívar], que, como todas as espanholas, é muito desenvolta e fala com facilidade e graça natural, dizia alguma grosseria de mau gosto dirigida à senhora Pardo Bazán. Muitos dos que estavam na plataforma de honra, atrás daquela escritora, aplaudiam em sinal de aprovação, o que me pareceu o cúmulo da descortesia e até da falta de patriotismo." (tradução nossa)
} 
haja o estabelecimento de uma hierarquização de saberes a partir de uma divisão sexual do trabalho, que ela considera ultrapassada.

É importante ressaltarmos que as considerações de Solo de Zaldívar a tocam pessoalmente, já que se dedicou ao trabalho intelectual por toda a vida, em um contexto social que interpreta a mulher como incapaz de desenvolver esse tipo de função profissional, destituindo-as da racionalização. Diante dessa ótica, é necessário pensar os paradoxos dos discursos das mulheres, em meio ao contexto sócio-histórico em que estão inseridas, como coloca Stella Maris Scatena Franco:

[...] se por um lado, viviam certos constrangimentos sociais e se enredavam a uma determinada tessitura comum de uma minoria excluída dos mecanismos oficiais do poder, por outro, eram brancas e das elites, sendo seus enunciados frequentemente afetados por esse lugar social. (FRANCO, 2017, p. 209)

Tal relação paradoxal que nos aponta Scatena Franco deve ser levada em consideração, pois lançamos olhar sobre um nicho específico, que são essas mulheres brancas de elite, que além dos privilégios sociais, são letradas e conseguem ultrapassar certos constrangimentos sociais para trazerem os seus escritos a público. Assim, durante a sessão do Congreso Pedagógico, Acosta de Samper assinala a sua concordância com o argumento de Pardo Bazán:

... y escuchamos a la señora Pardo Bazán leer una hermosa memoria en defensa del derecho y de las aptitudes de la mujer para desempeñar cargos públicos, hoy reservados exclusivamente al varón. En España se nota una posición decidida contra todo lo que tienda a elevar a la mujer intelectualmente; y esto no sólo entre la mayor parte de los hombres de letras; salvo honrosas excepciones, sino también, triste es decirlo, entre las mujeres $^{12}$ (ACOSTA DE SAMPER, 1893, II, p. 157).

Ao colocar que o rechaço à ocupação do mundo das letras não está restrito apenas aos homens, mas às mulheres também, Soledad aponta uma falta de irmandade entre as colegas de profissão. A dificuldade de inserção das mulheres na esfera pública é latente ao explorarmos a confraternização na casa de Pardo Bazán, em que poucas mulheres figuraram entre as convidadas, ao que Soledad descreve como apenas ela e sua filha Blanca. Por mais que critique a situação de

12 “...e escutamos a senhora Pardo Bazán ler uma bela memória em defesa do direito e das aptidões da mulher para desempenhar cargos públicos, hoje exclusivamente reservados ao varão. Na Espanha, nota-se uma posição decidida contra tudo o que tende a elevar a mulher intelectualmente; e isto não só entre a maior parte dos homens de letras; salvo honrosas exceções, mas também, é triste dizer, entre as mulheres.” (tradução nossa) 
desigualdade entre os gêneros, Pardo Bazán acaba por reforçá-la à medida que não abre espaço para essas mulheres.

Abre-se o questionamento sobre qual mulher deve tomar esse lugar, em meio aos "hombres de letras". Acosta de Samper deixa claro que poucas ocupam esses espaços como ela o faz. A defesa de colocação no mercado de trabalho é lançada sobre as mulheres burguesas, pois as mais pobres já ocupavam os afazeres subalternos nos espaços públicos a fim de garantirem a sua subsistência. Isto posto, a reflexão postulada é sobre o direito do exercício intelectual por parte das mulheres das camadas mais altas da sociedade.

Durante o congresso, a escritora colombiana demonstra ser empática com essa perspectiva inclusiva:

\begin{abstract}
Para dar fuerza, valor y emulación a las mujeres cuyas madres y abuelas han carecido casi por completo de educación, en mi humilde concepto creo que debería empezarse por probarles que no carecen de inteligencia y que a todas luces son capaces de comprender lo que se les quiera enseñar con la misma claridad que lo comprenden los varones. ${ }^{13}$ (ACOSTA DE SAMPER, 2011)
\end{abstract}

Diante de uma plateia controversa, Soledad traz a perspectiva de que homens e mulheres possuem as mesmas capacidades intelectuais, sendo capazes de compreender o conhecimento e transmiti-lo aos demais. Há um cuidado em colocar a sua fala como menos assertiva ao introduzir a expressão "mi humilde concepto", em uma estratégia de "pedir licença" para falar. Se as mães e avós das mulheres presentes não tiveram acesso à educação formal, Soledad apresenta como possibilidade a oportunidade dada à geração jovem como uma forma de reversão desse quadro. Vale refletirmos sobre a discussão empreendida por Pardo Bazán e Acosta de Samper ser um dos pontos de discussão do movimento feminista, que emergiu em meio a esse contexto, desenvolve a sua primeira onda a partir da proposta de cidadania estendida às mulheres. $\mathrm{O}$ movimento, concebido na Inglaterra pós Revolução Industrial, teve como uma das bandeiras mais conhecidas o acesso ao voto feminino. Isto fez com que essas mulheres fossem reconhecidas sob o nome de sufragistas.

\footnotetext{
13 "Para dar força, coragem e emulação às mulheres cujas mães e avó não acessaram a educação formal, no meu humilde entendimento, penso que se deveria começar por provar-lhes que não são desprovidas de entendimento e que são claramente capazes de compreender o que se lhes queira ensinar com a mesma clareza que os homens o compreendem." (tradução nossa)
} 
Finalizamos a participação de Acosta de Samper e Pardo Bazán no Congresso com a declaração do guatemalteco Juan Fernández Ferráz ao responder o espanhol Horacio Bentabol, que havia discutido a falácia da suposição de debilidade genética das mulheres, ao criticar a memória apresentada pela escritora alemã Bertha Wilhelmi de Dávila, que discutiu a aptidão da mulher para o exercício de todas as profissões. Fernández Ferráz coloca que

\begin{abstract}
¡Mujeres como, la Sra. Whilelmi, Pardo Bazán, la Arenal, como la eminente escritora colombiana Soledad Acosta de Samper, salvan á su sexo de la tacha de inferioridad que á él se le atribuye, y, señores, no hay que olvidarse que á los impulsos generosos y á las altas doses intelectuales de una mujer, educada por una mujer también, se debe la realización del descubrimiento con que el sublime Loco completó en el siglo XV el mundo, la obra de Dios, hasta entonces sólo en la mitad conocido de los hombres y cuyo cuarto centenario estamos celebrando y honrando la memoria del gran hombre y de la gran Reina con estos Congresos, exposiciones y festejos, que nos impulsionan todos á realizar también la obra de redención y aprovechamiento para bien de la vida, de este otro nuevo mundo de la humanidad, la mujer, el más bello y encantador sin duda de los dos hemisférios racionales. Edúquese é instrúyase convenientemente á la mujer, y habremos completado, el mundo intelectual humano! ${ }^{14}$ (ACOSTA DE SAMPER, 1893, II, p. 154)
\end{abstract}

Ao descrever uma série de mulheres intelectuais consagradas, Fernández Ferráz propõe uma quebra do discurso da debilidade do gênero feminino, lançando mão do exemplo de como uma mulher, educada por outra, teria permitido a conquista do Novo Mundo. Fernández Ferráz fala em um mundo que se tornaria completo a partir do momento em que homens e mulheres fossem educados formalmente, rechaçando a ideia de uma inferioridade intelectual feminina $a$ priori, fosse genética ou cultural. Destarte, acaba por dialogar com Acosta de Samper que entende a educação feminina como uma ferramenta de desenvolvimento de um Estado-nação em busca do alcance do estado de civilização. Essa declaração nos é cara para pensarmos o quão complexo foi esse encontro, diante de propostas tão antagonistas oferecidas pelos intelectuais presentes.

Se não devemos incorrer no risco de que é necessário o reconhecimento masculino para que mulheres ganhem espaços de fala e escuta, por outro lado, é importante ter como premissa que

\footnotetext{
14 "Mulheres como a Sra. Whilelmi, Pardo Bazán, Arenal e como a eminente escritora colombiana Soledad Acosta de Samper, salvam o seu sexo da mácula de inferioridade que ele lhe atribui, e, senhores, não se esqueçam dos impulsos generosos e as altas doses intelectuais de uma mulher, educada por uma mulher também, deve-se a realização do descobrimento do mundo em que o sublime Louco completou no século XV, a obra de Deus. Até então apenas a sua metade era conhecida dos homens e cujo quarto centenário estamos celebrando e honrando a memória do grande Rei e da grande Rainha com estes Congressos, exposições e festejos, que nos impulsionam a realizar também a obra de redenção e aproveitamento para o bem da vida, deste outro novo mundo da humanidade: a mulher, o mais belo e encantador elemento, sem dúvida dos dois hemisférios racionais. Que se instrua convenientemente a mulher, e teremos completado, o mundo intelectual humano!" (tradução nossa)
} 
o espaço conquistado por intelectuais e escritoras como as autoras citadas deve-se à inserção destas em redes de sociabilidade masculinas.

\title{
“Las hijas del pueblo" e uma concepção profissionalizante da educação
}

Soledad Acosta de Samper defende uma formação profissional e intelectual das mulheres pautada nas mesmas diretrizes intelectuais da educação dos homens, como demonstra em seu discurso Concepto y límites de la educación de la mujer y de la aptitud profesional de ésta, apresentado no Congreso Pedagógico hispano-lusitano-americano. Ao discutir "la educación de la hijas del pueblo", a escritora colombiana coloca que

\begin{abstract}
Aquí en América ¿no seria, por ventura, una obra digna de la atención de los Gobiernos el tratar de educar en las escuelas públicas, no señoritas cantatrices y sabias botánicas y físicas, sino honradas trabajadoras que saliesen de esos planteles de educación, sabiendo hábilmente un oficio, como el de bordar, hacer encajes, trabajar en obras de costura, según las reglas del arte? ¿Por qué se empeñan los mandatarios en producir mujeres inútiles, ó más bien perniciosas para la sociedad, en lugar de niñas trabajadoras que llevarán á sus familias el conocimiento de industrias nuevas entre nosotros, y qué las pudieran dar el pan cotidiano? ${ }^{15}$ (ACOSTA DE SAMPER, 1880, p. 19)
\end{abstract}

Ao trazer uma crítica ao governo colombiano de que os governantes não se empenhariam em produzir mulheres trabalhadoras, dedicando-se em contrapartida a formação de "mujeres inútiles", a escritora coloca a necessidade de se pensar uma educação formal para as mulheres que respeite o status quo por meio de ofícios como bordado e costura, segundo o que ela chama de regras da arte.

Acosta de Samper complementa a sua argumentação com a perspectiva de uma educação profissionalizante.

[...] En vez de traer tantos maestros de literatura para los colegios ¿por qué no hacer venir maestros para enseñar industrias lucrativas á los hijos del pueblo, y sobre todos a las hijas

\footnotetext{
15 “Aqui na América não seria, porventura, uma obra digna da atenção dos governos a educação nas escolas públicas, não de cantoras e sábias botânicas e físicas, mas honradas trabalhadoras que saíssem das escolas sabendo habilmente um ofício, como o de bordado e costura? Por que se empenham os governantes em produzir mulheres inúteis ou perniciosas para a sociedade, ao invés de trabalhadoras que levarão novos conhecimentos para a sua família e assim, garantir o pão de cada dia?" (tradução nossa)
} 
del pueblo, expuestas á tantas miserias físicas y morales, por falta de saber ocupar con buen provecho? ${ }^{16}[\ldots]$ (ACOSTA DE SAMPER, 1880, p. 19)

Em um primeiro momento, soa contraditório a reflexão de que seria um excesso a existência de professores de literatura por uma intelectual. Mas o que está em jogo em seu discurso é a ideia de uma funcionalidade para a educação, de modo que ela se torne rentável para todas as "filhas do povo". Para Acosta de Samper, a ausência de uma formação profissional corrobora para a permanência da miséria, que atingiria os colombianos tanto física quanto moralmente. Há intrínseca nesse discurso uma fragilidade de caráter, que seria alinhada à condição de pobreza. Porém, quem são "los hijos del pueblo"? A autora transparece uma divisão na sociedade colombiana a partir dessa interpretação.

Apelamos al buen sentido de nuestros Gobiernos, y pedimos, en nombre de LA MUJER COLOMBIANA, que se medite seriamente en este asunto, y que se procure poner un pronto remedio al erróneo sistema de educación de las clases pobres. El Gobierno es un segundo padre del pueblo, y éste tiene el derecho de exigir de él que no solamente le dé una vida intelectual, abriéndole las fuentes de la ciencia, sino que tienen el DEBER de darle los medios de subsistir honradamente, enseñándole industrias y procurándole ocupación lucrativa, benéfica y meritoria. [...] Abrid escuelas profesionales, no de artes de adorno, sino de utilidad; plantead talleres en donde puedan aprender los pobres un oficio, y habreis merecido más de la patria que con todos los discursos de ordenanza del VEINTE DE JULIO. ${ }^{17 "}$ (ACOSTA DE SAMPER, 1880, p. 19)

Acosta de Samper dá continuidade para a discussão clamando para que se pense um sistema de educação próprio para as classes pobres, demarcando a sua interpretação de necessidade para uma educação profissionalizante. Ao criticar as escolas de artes, dizendo que é necessária a abertura de escolas "de utilidad", a escritora aponta para um esforço que esses colombianos não dependam do governo, esse que seria um "segundo padre del pueblo" e, portanto, deveriam darlhes meios de subsistir.

\footnotetext{
16 "Ao invés de trazer professores de literatura para as escolas porque não fazer vir professores que ensinam habilidades lucrativas aos filhos do povo, e sobretudo às filhas do povo, expostas a tantas misérias físicas e morais por falta de se ocupar com algo proveitoso?” (tradução nossa)

17 "Apelamos ao bom senso de nossos governos, e pedimos, em nome da MULHER COLOMBIANA, que se reflita seriamente sobre este assunto, e que se procure um remédio rápido ao errôneo sistema de educação das classes pobres. O Governo é um segundo pai do povo, e este tem o direito de exigir dele que não somente lhe dê uma vida intelectual, abrindo-lhe as fontes da ciência, mas têm o DEVER de lhe dar os meios de subsistir honradamente, ensinando-lhe habilidades e procurando-lhe um emprego digno e benéfico. [...] Abrir escolas profissionais, não de artes, mas de utilidade cotidiana; levantai oficinas onde possam aprender os pobres um ofício, e haverá merecido mais da pátria que com todos os discursos de ordenança do VINTE DE JULHO.” (tradução nossa)
} 
A veemência de seu discurso parte da premissa de que por mais que o acesso ao ensino público seja limitado, a criação de escolas profissionalizantes seria uma boa saída. Vale colocar que não se trata de uma proposta de sociedade igualitária em termos de classe ou de gênero. A rejeição aos estudos clássicos para essas mulheres é pensada de forma a manter os grupos trabalhadores em suas funções. O que está colocado em xeque é a preocupação de formação de uma população letrada e, dessa forma, uma ausência de mão-de-obra subalterna que sirva às damas da sociedade como ela. (ARBELÁEZ, 2016, p. 72-73.)

Saliento essa demarcação social do seu discurso, pois a apropriação de sua trajetória pelos movimentos feministas na década de 1990, por vezes, a identifica como uma defensora da educação universal para as mulheres e precursora do feminismo. Tal análise acaba por relevar questões pungentes das sua atuação, que corrobora para o contexto social da época com algumas ressalvas. (LIMA, 2017)

Por outro lado, Acosta de Samper joga com o que é esperado que uma mulher faça em seu cotidiano, como boa católica deixa transparecer sua religiosidade em seus escritos e aponta para uma certa fragilidade por ser mulher em determinadas situações. Ela indica qual a função social que a mulher tem exercido, bem como um devir, escolhido pela Divina Providência, que não tem se realizado por falta de possibilidades.

\begin{abstract}
La mujer del siglo que expira ha transitado por todas las veredas de la vida humana; ha sabido dar ejemplos no solamente de virtud, de abnegación, de energía de carácter, sino también de ciencia, de amor al arte, de patriotismo acrisolado, de heroísmo. Pero aún le falta mucho por cumplir la misión salvadora que le tiene señalada la Divina Providencia, y si deseamos hacerla comprender e instruirla en lo que se aguarda de ella, conviene enseñarle el camino que han llevado otras para que sepa escoger el que concuerde mejor con el carácter especial de cada una. ${ }^{18}$ (ACOSTA DE SAMPER, 2011, p. 12)
\end{abstract}

Dessa forma, Soledad se envolveu nesse jogo de tensões, de reiterações e quebras de protocolos, como bem colocou Franco (2017), ora aderindo a um discurso, ora relativizando-o. Afinal, o que estava em jogo não era tão somente a vontade das mulheres em si, mas o código de conduta e moral das sociedades às quais elas pertenceram e pelas quais circularam. A participação

\footnotetext{
18 "A mulher do século que expira, percorreu todas as veredas da vida humana; soube dar exemplos não só de virtude, de abnegação, de carácter enérgico, mas também de ciência, de amor à arte, de patriotismo acrítico, isolado de heroísmo. Mas ainda lhe falta muito cumprir a missão salvadora que lhe tem apontada a Divina Providência, e se desejamos fazê-la compreender e instruí-la no que se espera dela, convém mostrar-lhe o caminho que outras levaram para que saiba escolher o que melhor condiz com o caráter especial de cada uma.” (tradução nossa)
} 
delas no jogo social se articulou de modo mais complexo, tendo em vista as camadas de interação e circulação de saberes.

\section{Considerações Finais}

Enfim, a organização de redes de sociabilidade se valeu do conhecimento construído em rede, como uma teia que se espalhou aos borbotões, mediante interesses e negociações políticas. As fronteiras dos âmbitos público e privado foram borradas a fim de configurar conexões importantes, que extrapolam o além-mar. Os salões materializaram a inserção do mundo público no privado e vice-versa, a partir do momento em que o anfitrião abre as portas de seu lar para uma série de personalidades, que configuraram importante moeda de troca no jogo político. Tomamos como exemplo a visita de Acosta de Samper na casa Pardo Bazán como elemento importante para a materialização de sua inserção política e intelectual no mundo das letras espanhol, legitimandoa enquanto uma escritora consagrada, respeitada por seus pares. A escritora colombiana recorreu ao discurso de sua própria consagração, em seus escritos, afirmando para público leitor de Viaje a España en 1892, que ocupava o lugar que lhe é devido.

Nesse campo, o relato de viagem produzido por mulheres é marcado pelas bordas soltas dessa categoria fluida, que não conseguem ser fechadas em um grupo, apesar de partirmos da premissa de que se trata de um material produzido em primeira pessoa, factual, sobre a jornada pela qual a autora passou. (BORM apud HOPER, 2004)

Além das fronteiras borradas da categoria, temos o jogo de forças e poderes em volta da questão do papel da mulher enquanto escritora e sujeito histórico. Soledad Acosta de Samper é um exemplo desse campo fluido da escrita que perpassa a experiência pessoal em forma de relato em conjunto com informações históricas dos lugares por onde passa, legitimadas pela citação de historiadores e estudiosos. Por outro lado, ela borrou as fronteiras de gênero ao atuar em espaços tidos como masculinos, reiterando, por outro lado, a sua função social como mulher. 
Bibliografia

ACOSTA DE SAMPER, Soledad. La mujer. Bogotá: Imprenta de Silvestre \& Compañía, 1880.

. "Aptitud de la mujer para ejercer todas las profesiones. Memoria presentada en el Congreso Pedagógico Hispano-Lusitano-Americano reunido en Madrid en 1892". Revista de Estudios Sociales, Bogotá, n. 38, Jan./Abr. 2011. Disponível em: <http://www.scielo.org.co/scielo.php?script=sci arttext\&pid=S0123-885X2011000100014>. Acesso em: 12012020 .

Antonio María Silvestre, 1893.

. Viaje a España en 1892. Tomo I e II. Bogotá: Imprenta de

ACOSTA DE SAMPER, Blanca Leonor. Copia de algunas Cartas de Blanca Samper escritas durante un viaje a España 1892. Bogotá: Biblioteca Nacional de Colombia, 1892.

ARBELÁEZ, Olga. Salvar la nación: el feminismo doméstico de Soledad Acosta de Samper. Estudios de literatura colombiana, Saint Louis, n.38, pp. 57-77, Jan/Jun. 2016. Disponível em: <https://dialnet.unirioja.es/descarga/articulo/5322742.pdf>. Acesso em 12012020.

DUQUE, Tiago. Gêneros incríveis: identificação diferenciação e reconhecimento no ato de se passar por. 2013, 218 f. Tese (Doutorado em Ciências Sociais) - Departamento de Ciências Sociais, Universidade Estadual de Campinas, Campinas, 2013. Disponível em: <http://taurus.unicamp.br/bitstream/REPOSIP/280487/1/Duque_Tiago_D.pdf>. Acesso em 12012020.

ELIAS, Norbert. O processo civilizador: Uma história dos costumes. v. I. Rio de Janeiro: Jorge Zahar Editora, 1994.

FRANCO, Stella Maris Scatena. Peregrinas de outrora: viajantes latino-americanas no século XIX. Florianópolis: Editora Mulheres, /Santa Cruz Del Sul: Edunisc, 2008.

- Viagem e gênero: tendências e contrapontos nos relatos de viagem de autoria feminina. Cadernos Pagu, Campinas, n.50, Set. 2017. Disponível em: < https://www.scielo.br/scielo.php?pid=S0104-83332017000200508\&script=sci abstract\&tlng=pt $\quad>$; Acesso em 12012020.

Viagens e relatos: representações e materialidade nos périplos de latino-americanos pela Europa e pelos Estados Unidos no século XIX. São Paulo: Editora Intermeios, 2018.

HINCAPIÉ, Luz. Soledad Acosta de Samper en el cuarto centenario de América. Revista Credencial Historia, Bogotá, edição 213, 2007. Disponível em: $<$ http://www.banrepcultural.org/blaavirtual/revistas/credencial/septiembre2007/soledadacosta.ht m>. Acesso em: 12012020.

LEITE, Miriam L. M. . Mulheres Viajantes no Século XIX. Cadernos Pagu, Campinas/UNICAMP, v. 15, p. 129-143, 2000. Disponível em: <https://periodicos.sbu.unicamp.br/ojs/index.php/cadpagu/article/view/8635570>. Acesso em 1201 2020 . 
LIMA, Adriane Raquel Santana de. Educação para mulheres na América Latina: uma análise decolonial dos escritos de Nísia Floresta e Soledad Acosta de Samper. 38a Reunião Nacional da ANPEd. São Luís: UFMA, 2017.

ORDÓÑEZ, Montserrat. Prólogo Género, escritura y siglo XIX en Colombia: releyendo a Soledad Acosta de Samper. Bogotá: 2000. In: SAMPER, Soledad Acosta de. Novelas y cuadros de la vida suramericana. Bogotá: Editorial Pontifícia Universidad Javeriana, Uniandes, 2004.

SIRINELLI, Jean-François. Os intelectuais. In: REMOND, René. Por uma história política. Rio de Janeiro: Editora FGV, 2003.

SOUZA, Gilda de Mello e. O espírito das roupas: a moda no século dezenove. São Paulo: Companhia das Letras, 1987. 